\title{
Chemical Composition and Physico-Chemical Analysis of Eucalyptus Globulus Leave and Oil
}

\author{
Abayneh Kassahun", Gezu Feleke \\ Department of Chemistry, College of Natural and Computational Sciences, Debre berhan University, Debre berhan, Ethiopia
}

Email address:

abayneh2002@gmail.com (A. Kassahun)

${ }^{*}$ Corresponding author

\section{To cite this article:}

Abayneh Kassahun, Gezu Feleke. Chemical Composition and Physico-Chemical Analysis of Eucalyptus Globulus Leave and Oil. Science Journal of Chemistry. Vol. 7, No. 2, 2019, pp. 36-38. doi: 10.11648/j.sjc.20190702.11

Received: April 6, 2019; Accepted: May 17, 2019; Published: June 19, 2019

\begin{abstract}
Eucalyptus globulus grows well in different parts of the world. More than 300 species of this genus have been shown to contain volatile oil. Essential oil contains many hundred chemical elements and this advanced mixture of compounds offers the oil its characteristic fragrance and flavor. The investigation has been carried out to know the chemical composition, Physico-Chemical properties of essential oils and Eucalyptus globulus leave grown at Ankober woreda, Ethiopia. To extract the essential oil, the fresh leaves of Eucalyptus globulus were subjected to hydro distillation for 3 hours using a Clevenger-type apparatus and the percent yield was $2.1 \%$. Physico-chemical properties such as refractive index (1.451), relative density (0.925), optical rotation $\left(+8^{\circ}\right)$, Solubility, color and odour were determined. Physico-chemical analysis of Eucalyptus globulus leaves such as total ash, water soluble ash; acid insoluble ash, moisture content and $\mathrm{pH}$ were found to be (6.09), (2.18), (2.22), (35.32) and (5.43) respectively. The composition of essential oils of Eucalyptus globulus were analyzed using Gas Chromatography-Mass Spectroscopy (GC-MS). A total of twenty volatile components were identified in this work. The main components of the essential oils are Alpha-Pinene (25.55\%), D-Limonene (5.687\%) and Eucalyptol (55.43\%).
\end{abstract}

Keywords: Eucalyptol, Eucalyptus Globulus, Essential Oil, GC-MS, Physico-Chemical

\section{Introduction}

Eucalyptus globulus commonly known as blue gum grows well in different parts of the world and has been known of its rich ethno medicinal and therapeutic importance [1]. Eucalyptus globulus is an evergreen tallest tree and leaves are leathery in texture, hang obliquely or vertical shape [2].

Eucalyptus globulus is an extremely adaptable species which grows well on a variety of soils and in a variety of climates. In Ethiopia, it succeeds everywhere in the highlands and does best at altitudes from $1800-2600 \mathrm{~m}$ on loamy soils [3]. The genus Eucalyptus comprises over 600 species of trees; more than 300 species of this genus have been shown to contain volatile oil in their leaves [4].

Eucalyptus globulus oil has a history of wide application; as a pharmaceutical, antiseptic, repellent, flavoring, fragrance and industrial uses [2]. The main uses of the oil is for the pharmaceutical industry (those that are rich in 1,8-cineole), perfumery (those that are rich in citronellal) and for industrial use (those that have piperitone and $\alpha$ - phellandrene as their main constituents [4].

Essential oils are liquid merchandise of steam or water distillation of plant components (leaves, stems, bark, seeds, fruits, roots and plant exudates). An essential oil may contain many hundred chemical elements and this advanced mixture of compounds offers the oil its characteristic fragrance and flavor [5].

The main components of essential oils of Eucalyptus globulus are monoterpenes (1, 8-cineole, p-cymene, citronellal, citronellol, limonene, $\alpha$-phellandrene, $\beta$-phellandrene, $\alpha$-pinene, $\beta$-pinene, trans-pinocarveol, terpinolene, $\alpha$-terpineol, $\alpha$-thujene) and sesquiterpenes ( $\beta$-caryophyllene, $\beta$-eudesmol, globulol, spathulenol and virdiflorol). The chemical profile and main components of oils from eucalyptus leaves varied significantly between species to species. The monoterpenes, 1, 8- cineole and $\alpha$-pinene, are the main components in most species, while, E. citriodora is rich in citronellal $(49.5-87 \%)$ and citronellol (8$20 \%$ ). The content of 1, 8-cineole in eucalyptus oils ranges from $10-90 \%$ [6]. The extraction products may vary in quality, quantity and in composition according to climate, soil 
composition, plant organ, age and vegetative cycle stage [7].

Eucalyptus globulus essential oils are gaining increasing interest due to their varied commercial applications particularly as insect repellents, fragrant and traditional medicines. Despite the commercial prospects, till now only limited eucalyptus species have been studied in Ethiopia. Considering that the chemical composition, physicochemical properties of eucalyptus oils and leaves analysis has been carried out to find the feasibility for the extraction of medicinal quality eucalyptus oil.

\section{Materials and Methods}

\subsection{Preparation of Plant Material}

Fresh leaves of Eucalyptus globulus were collected and air-dried in the shade to protect from the direct sun light. The dried leaves were stored in paper bags until subjecting to hydro distillation and physico-chemical analysis. The identity of the plant specimen was confirmed by botanist at the department of biology in Debre Berhan University.

\subsection{Extraction of Essential Oils}

Extraction of oil from Eucalyptus globulus leaves were carried out by a hydro-distillation. Dried leaves (100 g) were weighed and hydro distilled for three hours using full glass Clevenger-type apparatus. The oil sample obtained from hydro distillation was freed from water by adding anhydrous sodium sulfate and stored in sealed vials at $4{ }^{\circ} \mathrm{C}$ until the analysis was made.

\subsection{Chemical Composition Identification}

Determination of the chemical composition of the extracted essential oil from Eucalyptus globulus was carried out by Gas Chromatography-Mass Spectroscopy (GC/MS). GC/MS analysis was performed with HP5890 series II coupled with mass spectrometry HP5972 series detector and an electron ionization system, equipped with a capillary column HP5 (30 m, $0.53 \mathrm{~mm}, 0.25 \mu \mathrm{m}$ films). The carrier gas was helium, with a gas flow of $0.5 \mathrm{~mL} / \mathrm{min}$. Oven temperature was kept at $50^{\circ} \mathrm{C}$ for 4 minutes and programmed to $280^{\circ} \mathrm{C}$ at a rate of $3^{\circ} \mathrm{C} /$ minutes. Injector temperature was $250^{\circ} \mathrm{C}$ and the detector temperature was $280^{\circ} \mathrm{C}$. Mass spectra were taken at $70 \mathrm{eV}$. The identification of the components separated by GC-MS was made by comparing the obtained mass spectra for each component with the values stored in mass spectra library Wiley $275 \mathrm{~L}$ and HP CHEM /database. The results were further confirmed by comparison of their retention indices of the compounds with that of literature data.

\subsection{Physico-Chemical Analysis of Eucalyptus Globulus Leaves}

The powder sample of Eucalyptus globulus leaves were subjected to evaluate its moisture content, $\mathrm{pH}$, total ash, water soluble ash and acid insoluble ash.

\subsubsection{Moisture Content}

A mass of $1 \mathrm{~g}$ of the powdered plant material was spread in a thin layer in the crucible of the moisture balance apparatus. Temperature was set at $100^{\circ} \mathrm{C}$. Plant material was kept under this temperature until the moisture content attained a constant value [8].

\subsubsection{Determination of Ph Levels}

One gram of sample was measured by an electrical balance and then transferred into $25 \mathrm{ml}$ conical flask; $25 \mathrm{ml}$ of distilled water was added and heated on hot plate to boil and left to cool down. The aqueous herbal extracts were filtered into $25 \mathrm{ml}$ volumetric flask and filled by distilled water to the mark and was determined by using a calibrated $\mathrm{pH}$ meter [9].

\subsubsection{Total Ash, Water Soluble Ash, Acid Insoluble Ash}

Total ash, water soluble ash and acid insoluble ash was carryout according to World Health Organization Quality control methods for herbal materials [10].

\subsection{Physico-Chemical Analysis of Essential oils}

The Physico-chemical properties such as refractive index, relative density, optical rotation, Solubility, color and odour were determined according to standard analytical methods recommended by Association of Official Analytical Chemists (AOAC) and British pharmacopoeia $[11,12]$.

\section{Results and Discussion}

The percentage yields of essential oil obtained from the hydro distillation of the leaves of Eucalyptus globulus was $2.1 \%$ ( $/ / \mathrm{w}$ based on the fresh leaves). There are many literatures that report about Eucalyptus globulus essential oil yields in different countries; for example, $0.8-1.21 \%, 1.87 \%$, $0.08-3.5 \%$ and $1.1 \%$ of essential oil are found in Ethiopia, Algeria, Bangladish, and India, respectively [13-15].

The leaf sample of Eucalyptus globulus and essential oils were tested for relevant physicochemical parameters and the results are presented in Tables $1 \& 2$ below.

Table 1. Physico-chemical characteristics of Eucalyptus Globulus leaves.

\begin{tabular}{ll}
\hline Physicochemical parameter & values \\
\hline Total ash & 6.09 \\
Water soluble ash & 2.18 \\
Acid insoluble ash & 2.22 \\
Moisture content & 35.32 \\
PH & 5.43 \\
\hline
\end{tabular}

Table 2. Physico-chemical characteristics of Eucalyptus Globulus essential oil.

\begin{tabular}{ll}
\hline Physico-Chemical Characteristics & Value \\
\hline Relative density & 0.925 \\
Refractive index & 1.451 \\
Optical rotation & $+8^{\circ}$ \\
Appearance & Colorless liquid \\
Odour & Aromatic \\
Solubility & Soluble in alcohol \\
Color & Colorless \\
\hline
\end{tabular}

From the result it was found that the characteristic 
properties of the oil, such as odour, solubility, color, relative density, optical rotation and refractive index were more or less in good agreement with the reported results in the literature $[3,14]$

The chemical composition of Eucalyptus globulus essential oil is shown in Table 3 below. Based on the GC/MS result, a total of twenty volatile components were identified from the essential oil. The main components of the essential oils are Alpha-Pinene (25.55\%), D-Limonene (5.69\%) and Eucalyptol (55.43\%).

Table 3. Percentage composition of the volatile oils of Eucalyptus globulus.

\begin{tabular}{llll}
\hline NO. & RT & compound & \% \\
\hline 1 & 6.149 & Alpha-Pinene & 25.55 \\
2 & 7.349 & Beta-Pinene & 0.81 \\
3 & 7.820 & Beta-myrcene & 0.54 \\
4 & 8.275 & Alpha-Phellandrene & 0.29 \\
5 & 9.023 & P-Cymene & 0.57 \\
6 & 9.198 & D-Limonene & 5.69 \\
7 & 9.522 & Eucalyptol & 55.43 \\
8 & 10.335 & Gamma-terpinene & 0.43 \\
9 & 11.492 & $\alpha$-Terpinolene & 0.35 \\
10 & 13.543 & Isopinocarveol & 0.43 \\
11 & 14.568 & Pinocarvone & 0.24 \\
12 & 15.800 & Alpha-terpineol & 0.57 \\
13 & 22.744 & $\alpha$-Terpineol acetate & 3.22 \\
14 & 25.186 & Alpha-Gurjunene & 0.23 \\
15 & 26.416 & Aromandendrene & 2.11 \\
16 & 27.279 & Alloaromadendrene & 0.48 \\
17 & 28.692 & Viridiflorene & 0.30 \\
18 & 31.209 & Epiglobulol & 0.47 \\
19 & 32.188 & (-)-Globulol & 1.84 \\
20 & 32.457 & Ledol & 0.25 \\
\hline
\end{tabular}

These results show that the volatile oil has a particular quantitative and qualitative chemical composition. The major component was Eucalyptol followed by Alpha-Pinene and DLimonene while $\alpha$-Terpineol acetate, Aromandendrene, and (-)-Globulol are minor components of Eucalyptus globulus oil. Eucalyptol determines the business value of the oil and its significance as a raw material for diverse industries.

\section{Conclusion}

In this study physicochemical analysis and essential oil composition of Eucalyptus globulus essential oil grown in Ankober woreda was analyzed. The result showed that Eucalyptol (55.43\%) is major constituent which is aromatic in nature and may be used as an important raw material for perfumery industries. This work also provides useful information about physicochemical properties of Eucalyptus globulus leaves and oils. However, our results are preliminary contributions to establish standard values of chemical profile and physicochemical parameters for local product.

\section{Acknowledgements}

The Authors are grateful to Debre Berhan University for financial and material support.

\section{References}

[1] Bachheti, R. Chemical composition and antibacterial activity of the essential oil from the leaves of Eucalyptus Globulus collected from Haramaya University, Ethiopia. Der Pharma Chemica, 2015, 7(2):pp. 209-214.

[2] Priyanka S. Smita V. Polly G. To Study the pharmacological effect and beneficial effect of Eucalyptus Globulus in different types of diseases. Int. J. of Res. in Pharmacology \& Pharmacotherapeutics, 2017, 6(1):pp. 81-88.

[3] SubramanianP. A. Abraha G. Kebede N. Yield, contents and chemical composition variations in the essential oils of different Eucalyptus globulus trees from Tigray, northern Ethiopia. JPBMS, 2012, 17 (11):pp. 1-6.

[4] Fathi E. Sefidkon F. Influence of drying and extraction methods on yield and chemical composition of the essential oil of Eucalyptus sargentii.J. Agr. Sci. Tech. 2012, 14: pp. 1035-1042.

[5] Divya A,. Biological activities of essential Oils. Research \& reviews: Journal of Pharmacognosy and Phytochemistry, 2015, 3 (1): pp. 16-18.

[6] Jinbiao Z. Min A. Hanwen W. Rex S. Deirdre L. Chemistry and bioactivity of Eucalyptus essential oils. Allelopathy Journal, 2010, 25 (2): pp. 313-330.

[7] Bachheti R. K. Chemical composition and antibacterial activity of the essential oil from the leaves of Eucalyptus Globulus collected from Haramaya University, Ethiopia. Der Pharma Chemica, 2015, 7(2):pp. 209-214.

[8] Koleilat M. Raafat K. El-Lakany A. Aboul-Ela M. Designing monographs for Rosmarinus officinalis $\mathrm{L}$. and Lavandula angustifolia $\mathrm{L}$. Two Lebanese species with significant medicinal potentials. Pharmacogn J. 2017, 9(4): pp. 452-474.

[9] Moses A. G. M. Leonard G. Erastus G. Henry R. Physical evaluation of selected eight medicinal herbs used for the treatment of diabetes, malaria and pneumonia in Kisii region, Southwest Kenya. Europ. J. Appl. Sci. 2013, 5(2): pp. 43-46.

[10] World health organization. Quality control method for herbal material. Geneva: World Health Organization (2011).

[11] Horwitz, W. Official methods of analysis of AOAC International; AOAC International: Gaithersburg, Md. (2000).

[12] British pharmacopoeia 2010; Stationery Office: London, 2009.

[13] Mohamed N. B. Ferhat M. A. Abdelkrim K. Fairouz S. Kerkadi W. Sadok B. M. Quality assessment of the essential oil from Eucalyptus globulus Labill of Blida (Algeria) origin. International Letters of Chemistry, Physics and Astronomy, 2014, 36:pp. 3 03315.

[14] Astaq M. K. Khatun, S. K Hossain M. L Rahman M. Characterization of the Eucalyptus (E. Globulus) leaves oil. Journal of the Bangladesh chemical society, 2012, 25(2): pp. 97100 .

[15] Joshi A. Sharma A. Bachheti R. Pandey D. P. A. Comparative study of the chemical composition of the essential oil from Eucalyptus globulus growing in Dehradun (india) and around the world. Orient. J. Chem. 2016, 32(1): pp. 331-340. 